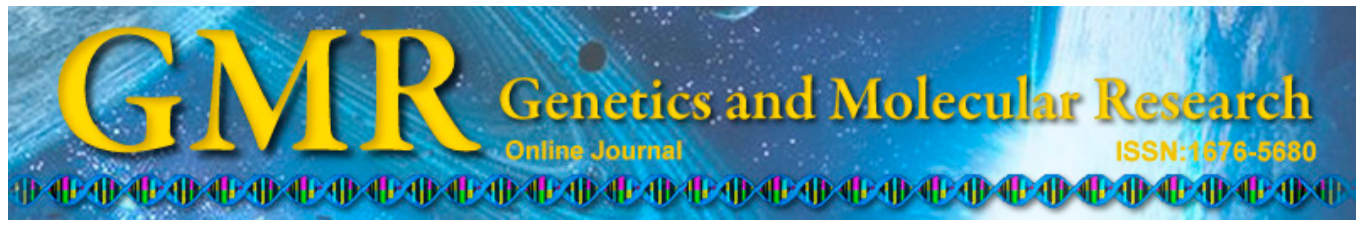

\title{
QTL mapping of forage yield and forage yield component traits in Sorghum bicolor $\mathbf{x}$ S. sudanense
}

\author{
Y.L. Liu*, L.H. Wang*, J.Q. Li, Q.W. Zhan, Q. Zhang, J.F. Li \\ and F.F. Fan
}

College of Agriculture, Anhui Science and Technology University, Fengyang, Anhui, China

*Theses authors contributed equally to this study. Corresponding author: Q.W. Zhan

E-mail: qwzhan@163.com

Genet. Mol. Res. 14 (2): 3854-3861 (2015)

Received July 31, 2014

Accepted November 6, 2014

Published April 22, 2015

DOI http://dx.doi.org/10.4238/2015.April.22.14

\begin{abstract}
The sorghum-sudangrass hybrid (Sorghum bicolor $\mathrm{x}$ $S$. sudanense) is an important forage crop. However, little is known about the genetic mechanisms related to forage yield and the 4 forage yield component traits in this forage crop. In this study, a linkage map was constructed with 124 assigned SSR markers using an $\mathrm{F}_{2}$ mapping population derived from the crossing of sorghum Tx623A and sudangrass Sa. Nine quantitative trait loci (QTLs) were detected for forage yield and the 4 forage yield component traits using inclusive composite interval mapping. Five fresh weight QTLs were identified and contributed $>50 \%$ of the total phenotypic variance. Of these QTLs, all showed additive and dominant effects, but most exhibited mainly dominant effects. These results will provide useful information for improvements in sorghum-sudangrass hybrid breeding.
\end{abstract}

Key words: Sorghum-sudangrass hybrid; Simple sequence repeat; Forage yield traits; Quantitative trait locus mapping 


\section{INTRODUCTION}

Sorghum (Sorghum bicolor) is ranked as the fifth most important grain crop worldwide; it is a major food staple and fodder resource (Xin et al., 2008). It also plays a huge role in the world market as a means of livelihood for millions of subsistence farmers (Duodu et al., 2003). Sudan grass (S. sudanense) and sorghum are diploids (i.e., $2 \mathrm{n}=20$ ) and distant species of the genus Sorghum. Sorghum and sudangrass are open pollinated and produce fertile offspring when crossed. The hybrid of sorghum and sudangrass (i.e., sorghum-sudangrass hybrid) is an annual forage crop with high nutritional quality, drought tolerance, lodging resistance, and high yield when compared to grain sorghum. The sorghum and sudangrass hybrid has been cultivated across 6800 hectares of land in China, to date (Yi et al., 1999).

The identification of quantitative trait loci (QTL) affecting agronomically important traits was conducted to understand their underlying genetic mechanisms and the genetic basis of their complex interactions (Srinivas et al., 2009). With the rapid development of molecular markers and linkage maps, it is possible to identify QTLs that control agronomic traits in sorghum. In recent years, a number of sorghum QTLs related to flowering time (Lin et al., 1995; Shiringani et al., 2010; El Mannai et al., 2012), drought resistance (Crasta et al., 1999; Xu et al., 2000), disease resistance (Nair et al., 2005; Wu et al., 2007; Wu and Huang, 2008), crop yield (El Mannai et al., 2012; Rajkumar et al., 2013), protein digestibility (Winn et al., 2009), sugar production (Jordan et al., 2004), plant height, and stem diameter (Lin et al., 1995; Jordan et al., 2004; Jang et al., 2006; Shiringani et al., 2010; Zou et al., 2012) were identified. To date, most of the research has focused on these traits in relation to resistance, crop yield, and plant height. However, there are limited studies investigating sorghum forage traits, especially with regard to the sorghum and sudangrass hybrid. To our knowledge, there has only been one report on the QTL mapping of agronomic traits in the Sorghum bicolor x S. sudanense hybrid. Lu et al. (2011) identified 48 QTLs of 10 agronomic traits in an $\mathrm{F}_{2}$ population of a sorghum 314A and sudangrass 2002GZ-1 hybrid using amplified fragment length polymorphism (AFLP) and randomly amplified polymorphism DNA (RAPD) markers. Compared to AFLP and RAPD markers, simple sequence repeat (SSR) markers have more privileges for molecular assisted breeding (Yang et al., 1996).

In the present study, we constructed the first SSR genetic map of a sorghum-sudangrass hybrid. We also identified QTLs for forage yield and 4 forage yield component traits using an $\mathrm{F}_{2}$ population of the sorghum-sudangrass hybrid. These QTLs and the flanked markers will be useful tools for improving sorghum-sudangrass hybrid breeding.

\section{MATERIAL AND METHODS}

\section{Material}

Plants from the mapping population of the $\mathrm{F}_{2}$ population were descendants of a cross between sorghum Tx623A (i.e., female parent) and sudangrass Sa (i.e., male parent). The $\mathrm{F}_{1}$ hybrid plants were bagged for self-pollination, and the harvested $\mathrm{F}_{2}$ seeds were cultivated in the field in Fengyang County (China). In the summer of 2013, all generations of the mapping population (i.e., $\mathrm{P}_{1}, \mathrm{P}_{2}$, and $\mathrm{F}_{2}$ ) were cultivated in Fengyang County. 


\section{Forage yield trait analysis}

Ten plants were measured for $\mathrm{P}_{1}$ and $\mathrm{P}_{2} ; 184$ plants from the $\mathrm{F}_{2}$ population were measured. The mean, SE, range, and correlation between traits were calculated using the Excel software. Five forage yield traits were measured, including stem diameter (SD; i.e., maximum diameter of the main stem), fresh weight (FW), blade number (BN), tiller number (TN; i.e., number of tillers per plant), and plant height $(\mathrm{PH})$ (i.e., length from the base to the tip of the spike).

\section{Marker genotyping}

DNAs from the parent and $\mathrm{F}_{2}$ populations were extracted using the sodium dodecyl sulfate method (Zhen et al., 2007). A total of 924 SSR markers evenly distributed on 10 sorghum chromosomes were selected to survey polymorphisms in the parents. A $10-\mu \mathrm{L}$ polymerase chain reaction (PCR) mixture was utilized and composed of $2.0 \mu \mathrm{L}$ DNA (20 ng/ $\mu \mathrm{L}), 1.0 \mu \mathrm{L} 10 \mathrm{X}$ buffer $\left(20 \mathrm{mM} \mathrm{Mg}{ }^{2+}\right), 1.5 \mu \mathrm{L}$ primers $(2 \mathrm{pmol} / \mu \mathrm{L}), 1.0 \mu \mathrm{L}$ dNTPs $(1 \mathrm{mM})$,

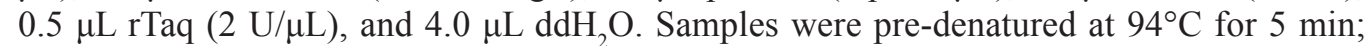
followed by 36 cycles of $30 \mathrm{~s}$ at $94^{\circ} \mathrm{C}, 30 \mathrm{~s}$ at $55^{\circ} \mathrm{C}$, and $80 \mathrm{~s}$ at $72^{\circ} \mathrm{C}$; and a final extension at $72{ }^{\circ} \mathrm{C}$ for $7 \mathrm{~min}$. PCR products were detected using silver staining on $8 \%$ nondenaturing polyacrylamide gel.

\section{Linkage map construction and QTL mapping}

The construction of a linkage map was employed by JoinMap 4.0. Linkage groups were initially determined by the results of pair-wise comparisons at a minimum likelihood of odds (LOD) value of 2-10. The best order was determined by comparing the goodness of fit of the resulting map for each tested order using a threshold of 1.0 and 2.0 for the linkage groups and loci, respectively. Marker sites significantly associated with traits were identified. The genetic map distance in centiMorgans (cM) was calculated using the Kosambi mapping function.

QTL IciMapping 4.0 was used to detect forage traits related to QTLs. A threshold of LOD $>2.5$ was used to identify the presence of putative QTLs. Inclusive composite interval mapping (ICIM) was performed to claim the putative QTLs (Wang et al., 2014).

\section{RESULTS}

\section{Molecular linkage map of the sorghum-sudangrass hybrid}

A total of 924 primers were screened between sorghum Tx623A and sudan grass Sa. We identified 180 primers that were polymorphic between the parents, and the percentage of polymorphism was $19.48 \%$. Ultimately, the linkage map of the sorghum-sudangrass hybrid was constructed by using 124 markers and covered $1196.2 \mathrm{cM}$ of the genome (Figure 1). The average interval among the markers was $10.4 \mathrm{cM}$ (Figure 1). The distribution of SSR loci on the linkage map was non-random. The number of markers on individual linkage groups varied from 9(chr8) to 21(chr1). 

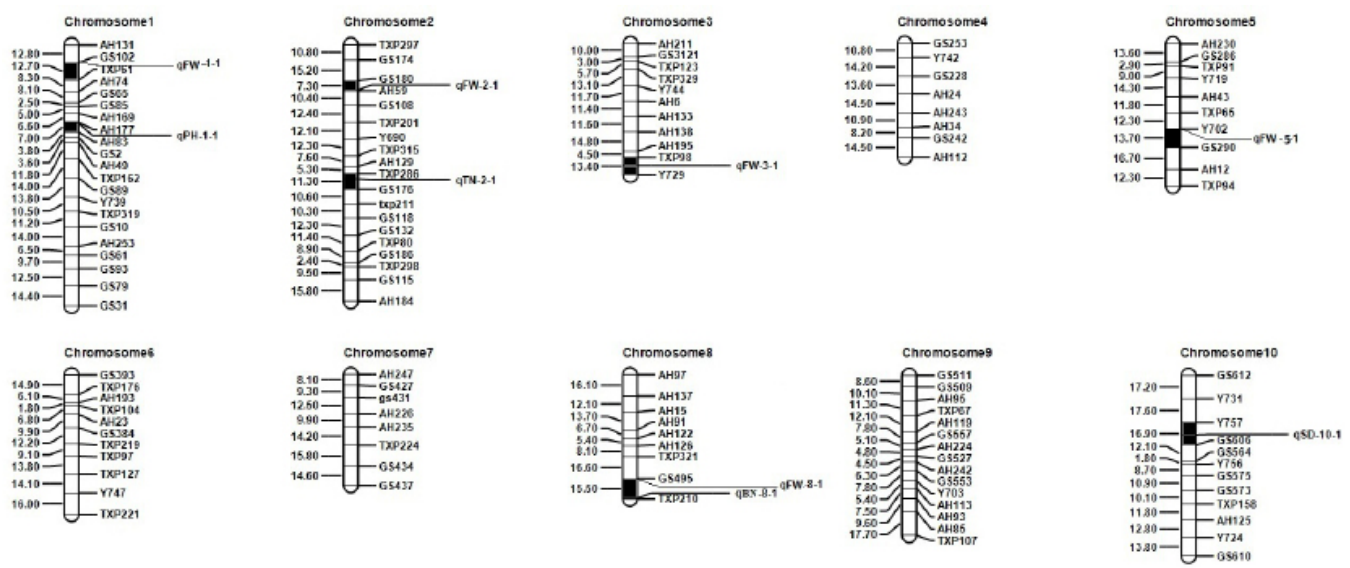

Figure 1. Position of QTLs associated with forage yield traits and 4 forage yield component traits in the $\mathrm{F}_{2}$ population. $\mathrm{FW}=$ Fresh weight per plant; $\mathrm{PH}=$ plant height; $\mathrm{TN}=$ tiller number; $\mathrm{SD}=$ stem diameter; $\mathrm{BN}=$ blade number.

\section{Trait analysis}

The 2 parents and $\mathrm{F}_{2}$ population were all measured for their phenotypic scores. The parental lines showed statistically significant differences for 5 traits. The value of skewness and kurtosis were small for the 5 traits in the $\mathrm{F}_{2}$ population. Thus, the 5 traits showed a normal distribution in the $\mathrm{F}_{2}$ population. Therefore, we can further map the location of the 5 traits in the population (Table 1).

Table 1. Statistical analysis of forage yield and 4 forage yield component traits in the population.

\begin{tabular}{|c|c|c|c|c|c|}
\hline \multirow[t]{2}{*}{ Trait name } & \multicolumn{3}{|c|}{$\mathrm{F}_{2}$ population } & \multicolumn{2}{|c|}{ Parents } \\
\hline & Mean & Skewness & Kurtosis & Tх623A & $\mathrm{Sa}$ \\
\hline Plant height (m) & $2.41 \pm 0.56$ & -0.37 & 0.16 & $1.21 \pm 0.26$ & $2.79 \pm 0.31$ \\
\hline Blade number & $11.10 \pm 1.43$ & -0.30 & 0.61 & $12.40 \pm 1.52$ & $9.00 \pm 1.00$ \\
\hline Fresh weight (kg) & $1.36 \pm 0.29$ & -0.16 & -0.50 & $0.52 \pm 0.13$ & $1.23 \pm 0.21$ \\
\hline Stem diameter $(\mathrm{mm})$ & $5.00 \pm 2.50$ & 0.58 & 0.14 & $20.6 \pm 0.31$ & $11.3 \pm 0.19$ \\
\hline Tiller number & $2.63 \pm 1.28$ & 0.75 & 0.30 & $1.50 \pm 0.31$ & $3.20 \pm 1.30$ \\
\hline
\end{tabular}

To understand the relationship between the 5 traits, correlation analyses were performed. The results showed that plant height was significantly and positively correlated with fresh weight, stem diameter, and tiller number. Blade number was positively correlated with fresh weight and stem diameter. Fresh weight and stem diameter had a significantly positive correlation. The results showed that the other 3 traits had a significantly positive correlation with fresh weight, with the exception of tiller number.

\section{QTL analysis}

Using the 5 traits and a genetic map, 9 QTLs were identified in the $\mathrm{F}_{2}$ population. These QTLs were distributed on chromosomes 1, 2, 3, 5, 8, and 10 (Table 2). The phenotypic variations of these QTLs were 7.46 to $29.49 \%$. 
Table 2. Correlation coefficients between five traits in the population.

\begin{tabular}{|c|c|c|c|c|c|}
\hline & Plant height & Blade number & Fresh weight & Stem diameter & Tiller number \\
\hline Plant height & 1 & & & & \\
\hline Blade number & 0.0625 & 1 & & & \\
\hline Fresh weight & $0.2430 * *$ & $0.2828 * *$ & 1 & & \\
\hline Stem diameter & $0.3893 * *$ & $0.2342 * *$ & $0.3001 * *$ & 1 & \\
\hline Tiller number & $0.3893 * *$ & 0.0068 & 0.1070 & $0.5472 * *$ & 1 \\
\hline
\end{tabular}

**Denote significant 0.01 probability.

\section{Plant height and blade number}

One QTL on chromosome 1, at about AH177-AH83, was found to be relevant to plant height. It exhibited additive and dominant effects, but mainly showed a dominant effect. The phenotypic variation of the QTL was 7.57\% (Table 3). Another QTL was related to blade number. It was localized on chromosome 8 between the marker interval GS495 and TXP210. This locus exhibited additive and dominant effects. The phenotypic variation for blade number was $7.66 \%$; the additive was -0.12 and the dominant was 0.78 .

\begin{tabular}{|c|c|c|c|c|c|c|c|}
\hline Trait name & Chromosome & QTL name & Marker interval & LOD & $\mathrm{R}^{2}(\%)$ & Additive & Dominant \\
\hline Plant height & 1 & $\mathrm{qPH}-1$ & AH177-AH83 & 3.14 & 7.57 & -0.07 & -0.32 \\
\hline \multirow[t]{3}{*}{ Blade number } & 8 & $\mathrm{qBN}-8$ & GS495-TXP210 & 3.35 & 7.66 & -0.12 & 0.78 \\
\hline & 1 & $\mathrm{qFW}-1$ & GS102-TXP61 & 2.79 & 7.46 & 0.03 & 0.16 \\
\hline & 2 & $\mathrm{qFW}-2$ & GS180-AH59 & 3.72 & 8.36 & 0.01 & -0.18 \\
\hline \multirow[t]{3}{*}{ Fresh weight } & 3 & $\mathrm{qFW}-3$ & ТXР98-Y729 & 4.09 & 14.66 & -0.15 & -0.11 \\
\hline & 5 & $\mathrm{qFW}-5$ & Y702-GS290 & 2.63 & 8.86 & -0.08 & -0.11 \\
\hline & 8 & $\mathrm{qFW}-8$ & GS495-TXP210 & 3.86 & 14.28 & -0.05 & 0.21 \\
\hline Stem diameter & 10 & qSD-10 & Y757-GS606 & 3.73 & 29.49 & -0.003 & 0.28 \\
\hline Tiller number & 2 & qTN-2 & TXP286-GS176 & 2.66 & 13.23 & 0.21 & -0.96 \\
\hline
\end{tabular}

Donor for the positive additive effect is from Tx623A, and donor for the negative additive effect is from Sa.

\section{Stem diameter and tiller number}

Only one QTL on chromosome 10, at about Y757-GS606, was found to be relevant to stem diameter. It exhibited additive and dominant effects. The phenotypic variation for the stem diameter was $29.49 \%$. Thus, it can be concluded that these QTLs are major genetic loci controlling plant height in this mapping population. A QTL related to till number was detected, which was located on chromosome 2 at the interval between markers TXP286 and GS176. The phenotypic variation for tiller number was $13.23 \%$. It showed additive and dominant effects, but the dominant effect was the main effect.

\section{Fresh weight}

Fresh weight is a direct measure of forage production. Five QTLs on chromosomes 1, 2, 3, 5, and 8, at about GS102-TXP61, GS180-AH59, Y729-TXP98, Y702-GS290, and GS495-TXP210 were detected to be relevant to fresh weight (Figure 1; Table 3). In these QTLs, the smallest and largest phenotypic variations for these QTLs were 7.46 and $14.66 \%$, respectively. All of these QTLs for fresh weight explained 53.62\% of the total phonotypic 
variation. Thus, it can be concluded that these QTLs are major genetic loci controlling fresh weight in this mapping population. These QTLs showed additive and dominant effects, but the dominant effect was the main effect, with the exception of qFW-3. Thus, the dominant effect played a major role in the fresh weight traits.

In the current research, we also identified one QTL that was relevant to 2 traits. For example, the 2 markers for fresh weight and blade number were located on the chromosome 8 interval between GS495and TXP210. In addition, the 2 QTLs had primarily positive and dominant effects.

\section{DISCUSSION}

The hybrid of the sorghum and sudangrass is an important forage crop. It has been widely cultivated in China and America (Zhan et al., 2008). In comparison to other crops (e.g., rice and maize), reports on QTL mapping for forage traits in this hybrid are still relatively lacking. Lu et al. (2011) first identified 3 QTLs pertaining to fresh weight using an $\mathrm{F}_{2: 3}$ population of the sorghum-sudangrass hybrid. These QTLs for fresh weight were detected on chromosomes 1, 3, and 6. In this study, we identified 5 QTLs pertaining to fresh weight. In these QTLs, qFW-1 and qFW-3 were mapped on the same region in the current and Lu et al. (2011) research. Thus, our research is consistent with the report by Lu et al. (2011). However, in the current research, we also identified 3 new QTLs for fresh weight. In these QTLs, qFW3 contributed $14.66 \%$ of the phenotypic variation and showed an additive effect. It may be a main-effect QTL for fresh weight. Therefore, further fine mapping of this QTL will be helpful for understanding the genetic basis for forage yield.

Pleiotropy (i.e., when one locus affects multiple phenotypic characteristics) has been an active topic of discussion in genetics. We co-located a fresh weight QTL and blade number QTL in the same region on chromosome 8. The co-location of QTLs has been reported in wheat and sorghum, especially for related traits (Mace et al., 2012; Lillemo et al., 2013). We also showed that fresh weight and blade number had a significant correlation. Blade number should be a component of fresh weight. Thus, we can easily understand why a QTL for the 2 traits were located within the same region. However, the molecular mechanism of co-location requires additional research.

Heterosis is a widely documented phenomenon in diploid organisms that undergo sexual reproduction. The genetic basis of heterosis has been debated for more than 100 years, and it is still not resolved. The dominance and overdominance hypotheses are the primary explanations for this phenomenon (Xiao et al., 1995; Meyer et al., 2010). Wancao No.3 was the $\mathrm{F}_{1}$ hybrid of the parents in previous research. Wancao No.3 showed great heterosis especially in forage yield (Zhan et al., 2010). However, little is known on the genetic mechanisms for the variety. In this research, we identified 9 QTLs pertaining to forage yield and 4 forage component traits. In these QTLs, most of them mainly showed a dominant effect, except qFW-3. Therefore, dominance is the major genetic basis of heterosis in the sorghum-sudangrass hybrid. The same mechanisms have also been identified in rice and maize (Garcia et al., 2008). This result suggests that in the process of parent selection for breeding, we should consider the complementation of parents for forage yield traits in the sorghum-sudangrass hybrid.

Mapping of agronomic traits provides the basis for molecular-assisted breeding. In the current research, we mapped 9 QTLs for 5 traits using SSR markers. Compared to previous research using RAPD and AFLP markers, SSR markers are easier to use in molecular-assisted 
breeding (Lu et al., 2011; Xu, 2011). Therefore, the flanked markers for these QTLs would be useful for molecular breeding in the sorghum-sudangrass hybrid.

\section{ACKNOWLEDGMENTS}

Research supported by the National Natural Science Foundation (\#31301383, \#31071470), Special Program of Scientific Research from China Agriculture Department (\#201503133), Key-construction Subject Plan of Anhui Province [WanJiaoMiKe(2014)28], and Planning Subject of the Twelfth Five-Year-Plan in the National Science and Technology for the Rural Development in China (\#2011BAD17B03).

\section{REFERENCES}

Crasta OR, Xu WW, Rosenow DT, Mullet J, et al. (1999). Mapping of post-flowering drought resistance traits in grain sorghum: association between QTLs influencing premature senescence and maturity. Mol. Gen. Genet. 262: 579-588.

Duodu KG, Taylor JRN, Belton PS and Hamaker BR (2003). Factors affecting sorghum protein digestibility. J. Cer. Sci. 38: 117-131.

El Mannai Y, Shehzad T and Okuno K (2012). Mapping of QTLs underlying flowering time in sorghum [Sorghum bicolor (L.) Moench]. Breed. Sci. 62: 151-159.

Garcia AA, Wang S, Melchinger AE and Zeng ZB (2008). Quantitative trait loci mapping and the genetic basis of heterosis in maize and rice. Genetics 180: 1707-1724.

Jang CS, Kamps TL, Skinner DN, Schulze SR, et al. (2006). Functional classification, genomic organization, putatively cis-acting regulatory elements, and relationship to quantitative trait loci, of sorghum genes with rhizome-enriched expression. Plant Physiol. 142: 1148-1159.

Jordan DR, Casu RE, Besse P, Carroll BC, et al. (2004). Markers associated with stalk number and suckering in sugarcane colocate with tillering and rhizomatousness QTLs in sorghum. Genome 47: 988-993.

Lillemo M, Joshi AK, Prasad R, Chand R, et al. (2013). QTL for spot blotch resistance in bread wheat line Saar co-locate to the biotrophic disease resistance loci Lr34 and Lr46. Theor. Appl. Genet. 126: 711-719.

Lin YR, Schertz KF and Paterson AH (1995). Comparative analysis of QTLs affecting plant height and maturity across the Poaceae, in reference to an interspecific sorghum population. Genetics 141: 391-411.

Lu XP, Yun JF, Gao CP and Acharya S (2011). Quantitative trait loci analysis of economically important traits in Sorghum bicolor x S. sudanense hybrid. Can. J. Plant Sci. 91: 81-90.

Mace ES, Singh V, Van Oosterom EJ, Hammer GL, et al. (2012). QTL for nodal root angle in sorghum (Sorghum bicolor L. Moench) co-locate with QTL for traits associated with drought adaptation. Theor. Appl. Genet. 124: 97-109.

Meyer RC, Kusterer B, Lisec J, Steinfath M, et al. (2010). QTL analysis of early stage heterosis for biomass in Arabidopsis. Theor. Appl. Genet. 120: 227-237.

Nair SK, Prasanna BM, Garg A, Rathore RS, et al. (2005). Identification and validation of QTLs conferring resistance to sorghum downy mildew (Peronosclerospora sorghi) and Rajasthan downy mildew (P. heteropogoni) in maize. Theor. Appl. Genet. 110: 1384-1392.

Rajkumar, Fakrudin B, Kavil SP, Girma Y, et al. (2013). Molecular mapping of genomic regions harbouring QTLs for root and yield traits in sorghum (Sorghum bicolor L. Moench). Physiol. Mol. Biol. Plants 19: 409-419.

Shiringani AL, Frisch M and Friedt W (2010). Genetic mapping of QTLs for sugar-related traits in a RIL population of Sorghum bicolor L. Moench. Theor. Appl. Genet. 121: 323-336.

Srinivas G, Satish K, Madhusudhana R, Reddy RN, et al. (2009). Identification of quantitative trait loci for agronomically important traits and their association with genic-microsatellite markers in sorghum. Theor. Appl. Genet. 118: 1439-1454.

Wang JK, Li HH, Zhang LY and Meng L (2014). Users' Manual of QTL IciMapping v4.0. Institute of Crop Science, CAAS, Beijing.

Winn JA, Mason RE, Robbins AL, Rooney WL, et al. (2009). QTL mapping of a high protein digestibility trait in Sorghum bicolor. Int. J. Plant Genomics 2009: 471853.

Wu Y and Huang Y (2008). Molecular mapping of QTLs for resistance to the greenbug Schizaphis graminum (Rondani) in Sorghum bicolor (Moench). Theor. Appl. Genet. 117: 117-124.

Wu YQ, Huang Y, Porter DR, Tauer CG, et al. (2007). Identification of a major quantitative trait locus conditioning resistance to greenbug biotype E in sorghum PI 550610 using simple sequence repeat markers. J. Econ. Entomol. 100: 1672-1678. 
Xiao J, Li J, Yuan L and Tanksley SD (1995). Dominance is the major genetic basis of heterosis in rice as revealed by QTL analysis using molecular markers. Genetics 140: 745-754.

Xin Z, Wang ML, Barkley NA, Burow G, et al. (2008). Applying genotyping (TILLING) and phenotyping analyses to elucidate gene function in a chemically induced sorghum mutant population. BMC Plant Biol. 8: 103.

Xu YB (2011). From Molecular Quantitative Genetics to Molecular Plant Breeding. China National Conference of Quantitative Genetics, Chengdu, 25-27.

Xu W, Subudhi PK, Crasta OR, Rosenow DT, et al. (2000). Molecular mapping of QTLs conferring stay-green in grain sorghum (Sorghum bicolor L. Moench). Genome 43: 461-469.

Yang W, de Oliveira AC, Godwin I and Schertz K (1996). Comparison of DNA marker technologies in characterizing plant genome diversity: variability in Chinese sorghums. Crop Sci. 36: 1669-1676.

Yi J, Lin XH, Dong ZK and Wang Z (1999). The sudan grass research progress at home and abroad. Inner Mongolia Prataculture 5: 1-6.

Zhan QW, Zhang TZ, Wang BH and Li JQ (2008). Diversity comparison and phylogenetic relationships of S. bicolor and S. sudanense as revealed by SSR markers. Plant Sci. 174: 9-16.

Zhan QW, Lin P, Li D and Li JQ (2010). Genetic analysis of main agronomic characters of Sorghum bicolor x Sorghum sudanense. J. Nanjing Agric. Univ. 33: 26-30.

Zhen Z, Li J, Sheng ZG and Peng ZY (2007). Comparison of different extraction methods of total DNA from sorghum. $J$. Anhui Agric. Sci. 36: 11758-11759.

Zou G, Zhai G, Feng Q, Yan S, et al. (2012). Identification of QTLs for eight agronomically important traits using an ultra-high-density map based on SNPs generated from high-throughput sequencing in sorghum under contrasting photoperiods. J. Exp. Bot. 63: 5451-5462. 